\title{
A IDEOLOGIA NEOLIBERAL E SUAS IMPLICAÇÕES NA GESTÃO DO ESTADO DO PARANÁ (2015-2018): A POLÍTICA EDUCACIONAL DE PRIVATIZAÇÃO DA EDUCAÇÃO SUPERIOR
}

Cyntia Danielle Pinto Gomes ${ }^{1}$, Patrícia L.L. Mertzig Gonçalves de Oliveira ${ }^{2}$, Camila Tecla Mortean Mendonça ${ }^{3}$, Maria Luisa Furlan Costa ${ }^{1}$.

${ }^{1}$ Universidade Estadual de Maringá - UEM, Maringa, PR. ${ }^{2}$ Universidade do Oeste Paulista - UNOESTE, Presidente Prudente, SP. ${ }^{3}$ Centro Universitário Cesumar - UNICESUMAR, Maringá, PR. E-mail: cyntiavcg@hotmail.com

\section{RESUMO}

Este debate busca discutir de que forma as ideias neoliberais influenciaram a política educacional da gestão do Estado do Paraná (2015-2018), com foco na Educação Superior, haja vista as reformas e tentativas de privatização das universidades estaduais paranaenses. Para esta análise, será utilizada a pesquisa bibliográfica e documental, favorecendo a reflexão sobre a influência dos organismos internacionais na educação brasileira. O pressuposto é que as políticas educacionais para esse nível de ensino envolvem diferentes atores, interesses e prioridades. Desse modo, as políticas, que deveriam ser de Estado, são, em contrapartida, de Governo, marcadas pelos anseios de um pequeno grupo fortemente influenciado pelo ideário neoliberal e com foco no mercado.

Palavras-chave: Ideologia neoliberal; Estado do Paraná; Educação Superior.

THE NEOLIBERAL IDEOLOGY AND ITS IMPLICATIONS IN THE MANAGEMENT OF THE STATE OF PARANÁ (2015-2018): THE EDUCATIONAL POLICY OF PRIVATIZATION OF HIGHER EDUCATION

\begin{abstract}
This debate seeks to discuss how neoliberal ideas influenced the educational policy of the State of Paraná (2015-2018), focusing on Higher Education, given the reforms and attempts to privatize state universities in Paraná. For this analysis, the bibliographical and documentary research will be used, favoring the reflection on the influence of the international organisms in the Brazilian education. The assumption is that educational policies at this level of education involve different actors, interests and priorities. Thus, the policies, which should be State, are, on the other hand, be government, marked by the yearnings of a small group strongly influenced by the neoliberal ideology and with a focus on the market.
\end{abstract}

Keywords: Neoliberal ideology; State of Paraná; Higher education. 


\section{INTRODUÇÃO}

Os fundamentos liberais, que encontram respaldo em produções de até quatro séculos atrás, mas que se aproximam principalmente das ideias originadas em Adam Smith, passaram, não raramente, a ocupar local de destaque nos discursos e nas ações políticas e governamentais da atualidade, ressurgindo como neo, um novo apontamento para a superação da crise econômica e de seu impacto nas mais diversas áreas (GENTILI, 1999). Em sua obra A Riqueza das Nações, Adam Smith, cuja primeira publicação é de 1776, apresenta a base principal dessa corrente, qual seja: a estimulação ao livre comércio e à concorrência não interferida. Isso seria possível, segundo o autor, a partir de recursos como a lógica da divisão do trabalho (SMITH, 1985).

Apesar das investidas neoliberais no cenário brasileiro, há que se destacar que as condições são totalmente diferentes daquelas emergidas do liberalismo. É notório, por exemplo, que, no país, ainda não é percebido um início nem tampouco sinais de uma sociedade igualitária, onde todos tenham as mesmas oportunidades. Dessa forma, o que se percebe é que as políticas que deveriam ser de Estado são políticas de Governo e que estas têm demonstrado uma incansável busca por melhorias, se espelhando nas estratégias e na organização das grandes potências americanas e européias, sob orientações dos Organismos Internacionais.

No campo educacional esta lógica não é diferente, pois a ideologia dominante não critica a universalização do acesso, que, a seu ver, não enfrenta nenhuma crise e sim visualiza a educação com características de não produtividade, eficiência e eficácia para o mercado de trabalho. Nesse sentido, Gentili (1999, p. 15) explica

Na perspectiva neoliberal, isto acontece porque a crise educacional não se reduz apenas à existência de um certo modelo de Estado, nem ao caráter supostamente corporativo das entidades sindicais. O problema é mais complexo: os indivíduos são também culpados pela crise. e é culpada na medida em que as pessoas ajeitaram corno natural e inevitável o status quo estabelecido por aquele sistema improdutivo de intervenção estatal. Os pobres são culpados pela pobreza; os desempregados pelo desemprego; os corruptos pela corrupção; os faceados pelas violência urbana; os sem- terra pela violência no campo; os pais pelo rendimento escolar de seus filhos; os professores pela péssima qualidade dos serviços educacionais. $O$ neoliberalismo privatiza tudo, inclusive também o êxito e o fracasso social (Grifos do autor).

Diante desse diagnóstico, segundo os neoliberais, é necessária uma reforma administrativa rápida, pois o sistema educacional sofre falhas graves e improdutivas, na prática pedagógica e na gestão administrativa. Sendo assim, as políticas educacionais, implantadas pela lógica neoliberal, defendem a necessidade de uma avaliação da qualidade dos sistemas e das Instituições Escolares e a produtividade educacional estabelecida pelo mercado de trabalho.

Isto é, a capacidade flexível de adaptação individual às demandas do mercado de trabalho. A função "social" da educação esgota-se neste ponto. Ela encontra o seu preciso limite no exato momento em que o indivíduo se lança ao mercado para lutar por um emprego. A educação deve apenas oferecer essa ferramenta necessária para competir nesse mercado. O restante depende das pessoas (GENTILI, 1999, p. 8-9).

Nesta ideologia, as instituições escolares devem ser pensadas e avaliadas como se fossem empresas produtivas cujo aluno e o conhecimento devem demonstrar eficiência, relacionando a educação com as necessidades do mercado de trabalho. Dessa forma, uma indagação se faz importante: para onde se desloca a função social da escola? Para os neoliberais a função da escola é unicamente a preparação para o mercado de trabalho, o restante depende de cada pessoa, seus méritos e oportunidades.

De acordo com Comblin (2000), há uma forte pressão para reduzir os gastos do Estado, diminuindo os impostos e contribuições sociais, as quais as vítimas da redução dos gastos são os serviços sociais. O resultado é: baixa a qualidade dos serviços como educação, saúde, programas sociais restritos a poucos; neste contexto, há um enxugamento da máquina pública que não volta 
a crescer na medida em que cresce as suas necessidades; isso tudo sem citarmos a má remuneração dos funcionários públicos.

Toda esta manobra se faz a fim de que o Brasil atenda ao modelo neoliberal, que já é implantado na maior parte dos países da Europa e nos Estados Unidos, o qual é caracterizado pela privatização dos serviços como saúde, educação e previdência. O Estado intervém somente na forma assistencial: trata-se antes de uma concessão benévola do Estado.

Assim, o Grupo de Pesquisa Educação a Distância e as Tecnologias Educacionais/CNPQ da Universidade Estadual de Maringá (UEM) estuda, dentre outras, temáticas relacionadas as políticas públicas e gestão da educação no Brasil. Dessa forma, o presente texto tem por objetivo discutir a influência de organismos internacionais na educação brasileira com ênfase nas universidades públicas do estado do Paraná no intuito de observar como o ideário neoliberal influencia as tomadas de decisões da gestão do Estado do Paraná (2015-2018), bem como a população de forma geral.

\section{METODOLOGIA}

A presente pesquisa utiliza como metodologia a pesquisa bibliográfica e documental. 0 Levantamento bibliográfico compreende textos e autores que subsidiam as reflexões teóricas a respeito da influência do Banco Mundial e dos Organismos Internacionais na educação brasileira. Já os documentos oficiais selecionados para este trabalho, tais como a Constituição federal de 1988, a Lei de Diretrizes e Bases da Educação Nacional (LDBEN), Lei no 9.394/96, servem para nortear as reflexões propostas e como estas emergem no campo do ensino superior usando de exemplo três Instituições de Ensino Superior (IES) Públicas vinculadas ao Estado do Paraná no em sua gestão (2015 - 2018). São elas: Universidade Estadual de Maringá (UEM), Universidade Estadual de Londrina (UEL) e Universidade Estadual do Oeste do Paraná (Unioeste), que tem lutado pela defesa da Universidade Pública.

\section{RESULTADOS}

Diante da conjuntura que vem desde a finalização da gestão do Estado do Paraná (20152018), as universidades públicas estão cada dia mais ameaçadas no que diz respeito a sua funcionalidade, organização, investimento público, autonomia e acesso, haja vista que o Estado, a partir da adoção da política Neoliberal, passou a cortar os investimentos da Educação Superior, seguindo as orientações dos Organismos Internacionais, especialmente o Banco Mundial (BM). Essa influência, no que se refere às medidas empregadas ao ensino superior, tem focado na diminuição dos gastos públicos. Os investimentos educacionais do BM não se darão na educação superior, devido à urgência na redução da pobreza, como afirma o documento:

As instituições de nível superior têm a responsabilidade principal de entregar as pessoas os conhecimentos necessários para desempenhar cargos de responsabilidade nos setores públicos e privados (...) Na maioria dos países as instituições de ensino superior também desempenham importantes funções sociais, já que contribuem para formar a identidade nacional (...) os investimentos nesse nível de ensino contribuem para aumentar a produtividade de trabalho e a produzir um crescimento econômico mais alto a longo prazo, elementos que são fundamentais para o alívio da pobreza (BANCO MUNDIAL, 1995, p.1).

Neste contexto, acreditamos que os investimentos devem ser na Educação Básica. Assim, as políticas dos Organismos Internacionais, aliadas às medidas descentralizadoras do Estado, contribuem para o processo de privatização das Instituições de Ensino Superior. Diante dessas afirmações, "[...] o incremento à integração com a economia mundial, a ênfase no papel do mercado na alocação de recursos, a diminuição do papel do Estado com relação tanto a economia quanto à área social dos serviços públicos em que se insere a educação superior (SGUISSARD, 
2000, p.18)", encontra-se como foco da política neoliberal, as quais estão em processo de implementação.

A reorganização da educação Superior no Brasil, quanto à sua oferta pelas instituições privadas, é algo novo, suas raízes têm início dos anos 90, mais especificamente nos Governos de Fernando Collor de Melo (1990-1992) e Fernando Henrique Cardoso (1995-2003) que já apresentavam propostas de reforma para as Universidades Públicas em um processo crescente de privatização das mesmas. Foi neste período que o Brasil abre suas fronteiras para o mercado externo e adota a política neoliberal a fim de estabilizar a economia, política esta que permanece até os dias atuais em nosso país. Junto com os empréstimos do BM, o Brasil recebe normativas que visam o crescimento econômico e a minimização da pobreza. Para atender a estas normativas, o país inicia várias reformas que culminam na promulgação de uma série de legislações, incluindo a LDBEN.

Em meio a esse processo, há um crescente aumento das IES particulares, devido a abertura que a nova LDBEN deu para a oferta da educação no país e também a necessidade de instituições que atendam aos professores, pois a partir da publicação desta legislação, passa a ser obrigatório que todos os professores da Educação Básica tenham formação em nível superior.

Esta é uma forma que o governo utiliza para direcionar os olhares da população para estas Instituições, precarizando, assim as Universidades Públicas, que diante desse contexto deixa de ter condições para a oferta da educação pública. A falta de recursos oficiais, a diminuição de salários e as péssimas condições físicas das universidades públicas são apenas exemplos do reflexo que as mudanças das últimas décadas têm causado no setor público educacional.

Nesse sentido, a autonomia das universidades, também está sendo entendida sob óticas diferentes. O Artigo 207 da Constituição Federal regulamenta que "As universidades gozam de autonomia didático-científica, administrativa e de gestão financeira e patrimonial, e obedecerão ao princípio da indissociabilidade entre ensino, pesquisa e extensão (CONSTITUIÇÃO FEDERAL, 1988)". Na LDBEN no 9.394/96, em seu artigo 53, observa-se que a autonomia universitária, assim como sua forma de organização e atribuições, também é regulamentada. Porém, o Estado se refere à autonomia no sentido da sua crescente desobrigação para com o financiamento do ensino superior público. Na verdade, uma universidade pública deve ser mantida com recursos estatais, porém, com liberdade na definição de seus programas, cursos, linhas de pesquisa, extensão de serviços a comunidades, entre outros. Ou seja, deve ser pública no que diz respeito ao acesso, a produção e construção de conhecimento e aos serviços que disponibiliza a comunidade. Deve agir com liberdade de pensamento, ideias, criações de intervenção sobre sua realidade social.

Sendo assim, é importante destacar que a política neoliberal, com o seu foco no mercado, contribui para o processo de privatização das universidades, pois seu objetivo é relacionar o ensino, pesquisa e extensão aos critérios de eficácia pelas regras da concorrência, por meio das múltiplas reformas educacionais, de dimensão e amplitude diferentes, destinadas a reduzir a intervenção do Estado na previsão de recursos orçamentários e a jogar para o mercado a administração da educação (BARROSO, 2004).

\section{DISCUSSÃO}

Diante desse contexto e analisando as ações na arena política da gestão do Estado do Paraná (2015-2018), podemos observar um governo que utiliza do ideário neoliberal na sua organização política. Isso se deve ao fato de que suas ideias estão sendo organizadas e são lançadas para a população que anseia pela manutenção dos seus direitos, uma vez que mesmo já garantidos pela Constituição acabam se perdendo em meio aos problemas de um governo que não tem como preocupação primordial a população, mas sim a manutenção do mercado. 
Dessa forma, a política educacional, baseada nos interesses e na manutenção no mercado, não apresentou sinais de uma valorização profissional para os servidores da educação, em especial aos professores, ou até mesmo a garantia de uma educação de qualidade. $O$ sistema de ajuste adotado pelo governo tem como principal objetivo utilizar as universidades para manutenção do capital, se pautando nos interesses de grandes empresários. Assim, a cultura empresarial invade as instituições da sociedade e provoca o enfraquecimento das esferas públicas, principalmente aquelas mais importantes para a conservação do direito de cidadania, como no caso da educação. Toda essa transformação faz da privatização, um componente central da ideologia neoliberal, que determina a estratégia daqueles que governam, transformando o público em propriedade privada.

O que chama a atenção não são as ações da gestão quando reduz gratificações ou congela salários de professores, mas sim, as justificativas plausíveis que este utiliza para justificar as mudanças incentivando a população a acreditar em seu discurso. Ora, se temos tantos problemas econômicos no Estado, o governo pode e deve cortar gastos para equilibrar as contas. Infelizmente esta é a leitura que o governo faz e tenta, por meio de um discurso ideológico, convencer a população, sem levar em consideração a importância social e formadora da educação e seu poder de transformação do indivíduo.

O Estado deveria entender a educação não como um gasto e sim como um investimento social e político e direito de todos, inclusive nas universidades. No entanto, o governo se exime de tal obrigação, pois a produção do conhecimento que não satisfazer o mercado é considerada desnecessária.

Os docentes das universidades públicas do Estado do Paraná estão em luta contra uma série de ataques do governo do estado. Benefícios não pagos, reajustes não feitos, previdência saqueada e muita repressão às greves e ocupações. Não é de se estranhar que o governo visa acabar com a autonomia universitária. Mais recentemente, o governo decidiu acabar com o regime de dedicação exclusiva dos servidores das universidades, que levaram a discussão para os Conselhos Universitários. Três das maiores entre as sete no estado, Universidade Estadual de Maringá (UEM), Universidade Estadual de Londrina (UEL) e Universidade Estadual do Oeste do Paraná (Unioeste), decidiram por não enviar os dados e manter o controle da folha dentro da universidade. Desse modo, o governo, em medida retaliativa, decidiu bloquear as verbas dessas três universidades.

Nesse contexto, as universidades são lesadas no que diz respeito aos atendimentos que realiza e, como consequência, a qualidade dos trabalhos é diretamente prejudicada. E o objetivo é um só: precarizar o atendimento para convencer a população que o gasto público nas universidades é muito alto e que o retorno econômico não é recompensado. Mais uma vez, um olhar de educação como mercadoria.

\section{CONCLUSÃO}

A discussão realizada aponta que, com a intenção de manutenção do mercado, a ideologia neoliberal instituída no Brasil desde a década de 90 , contribuiu para o processo de privatização das universidades públicas. A promulgação da LDBEN, Lei no 9.394/96, em seu artigo 70 afirma que "o ensino é livre à iniciativa privada" e legisla sobre as condições para tal. Desta maneira, ainda que não tenha havido ainda uma privatização propriamente dita da educação superior, observamos uma diminuição proporcional dos investimentos estatais na educação pública aliada a um crescimento extraordinário do setor privado que investe no mercado de ensino, ou seja, é uma questão de tempo para que as universidades iniciem o processo de privatização.

O momento político atual do Brasil perpassa por uma crise em todos os setores, porém, na educação, é notório os ataques e investidas de privatização das Instituições. Sendo assim, para que as universidades possam sobreviver a estas ofensivas é preciso que sua autonomia, principalmente aquela relacionada ao ensino, pesquisa e extensão seja fortalecido. Além disso, é 
de suma importância uma reforma política que possa romper com os modelos e orientações do Banco Mundial e com os governos que corroboram com o ideário neoliberal.

No que diz respeito ao Estado do Paraná, o que se percebe é que o ideário neoliberal está inserida em todas as ações politicas e econômicas do governo. A tentativa de privatização das universidades faz parte das estratégias que o governo adota para que a educação continue sendo uma mercadoria, onde o empresariado tem grande participação e mais que isso, deturpando a verdadeira função da educação enquanto construção do sujeito e do conhecimento.

Dessa forma, o país necessita de uma política educacional onde os profissionais sejam valorizados nos seus cargos, na sua profissão, na sua formação. Que as Instituições tenham a infraestrutura desejada para a construção do saber. Isso é dever do Estado e essa relação de parceria público-privada defendida pelos neoliberais não garante qualidade, mas sim uma transferência das obrigações do governo para outros que assumem esse papel, redirecionando os rumos da educação brasileira.

\section{REFERÊNCIAS}

BANCO MUNDIAL. La enseñanza superior: las lecciones derivadas de la experiencia. Banco Mundial. Washington, 1995, p.1-16.

BARROSO, J. Os novos modos de regulação das políticas educativas na Europa:da regulação do sistema a um sistema de regulações. Educação em Revista, Belo Horizonte, v. 39,p. 19-28, jul. 2004.

BRASIL. Constituição (1988). Constituição da República Federativa do Brasil. Brasília, DF, Senado, 1988.

BRASIL. Leis de Diretrizes e Bases da Educação Nacional. 1996. Disponível em: <http://www.planalto.gov.br/Ccivil_03/leis/L9394.htm> Acesso em: 31. Jul.2018.

COMBLIN, J. O neoliberalismo: ideologia dominante na virada do século. 2.ed. Petrópolis: Vozes, 2000.

GENTILI, P. A. A. Neoliberalismo e educação: manual do usuário. In: SILVA, Tomaz Tadeu da; GENTILI, Pablo A. A. (Org.). Escola S. A.: quem ganha e quem perda no mercado educacional do neoliberalismo. Brasília: CNTE, 1999. p. 9-49.

SGUISSARDI, V. Educação superior: o banco mundial reformará suas teses e o Brasil reformará sua política? Educação Brasileira. Brasília, v.22, n.45, p.11-53.

SMITH, A. A Riqueza das Nações: investigação sobre sua natureza e suas causas, São Paulo: Nova Cultural, $2^{\mathrm{a}}$ edição, 1985. 